\title{
FENOMENOLOGI KOMUNIKASI TERAPEUTIK FAMILY CAREGIVER KOMUNITAS PEDULI SKIZOFRENIA INDONESIA (KPSI)
}

\author{
Shofia Nur Rahma ${ }^{1 *}$, Rini Riyantini², Dian Tri Hapsari ${ }^{3}$ \\ 1,2,3 Universitas Pembangunan Nasional Veteran Jakarta, Jakarta, Indonesia \\ *shofiaarahma10@gmail.com
}

\begin{abstract}
Therapeutic communication has an important role to help the recovery process of People With Schizophrenia (ODS) who have symptoms of hallucinations and delusions that can lead to a tendency to have difficulty communicating to withdraw from the social environment. Therapeutic communication is a form of communication aimed at the therapeutic process and patient healing. Phenomenology is used as a method and therapeutic communication as a theory in this study. The data collection method was carried out through online interviews using WhatsApp voice calls to 6 ODS family caregiver informants. The results of this study indicate that the experience of therapeutic communication carried out by family caregivers in the form of interpersonal communication can help the ODS awareness process regarding schizophrenia as indicated by ODS' willingness to take medication regularly, as well as communication in the form of showing acceptance, listening carefully, and emotional regulation when communicating with ODS can provide appropriate treatment when ODS has relapse symptoms so that it can help the process of developing ODS.
\end{abstract}

Keywords: therapeutic communication, family caregiver, ODS, awareness process, development process

\begin{abstract}
Abstrak
Komunikasi terapeutik memiliki peranan penting untuk membantu proses pemulihan Orang Dengan Skizofrenia (ODS) yang memiliki gejala halusinasi dan delusi yang bisa mengakibatkan kecenderungan untuk kesulitan berkomunikasi hingga menarik diri dari lingkungan sosial. Komunikasi terapeutik merupakan salah satu bentuk komunikasi yang bertujuan untuk proses terapi dan penyembuhan pasien. Fenomenologi digunakan sebagai metode dan komunikasi terapeutik sebagai teori dalam penelitian ini. Metode pengumpulan data dilakukan melalui wawancara daring menggunakan voice call WhatsApp kepada 6 orang informan keluarga (family caregiver) ODS. Hasil penelitian ini menunjukkan bahwa pengalaman komunikasi terapeutik yang dilakukan family caregiver dalam bentuk komunikasi interpersonal dapat membantu proses penyadaran ODS mengenai penyakit skizofrenia yang ditunjukkan dengan kemauan ODS untuk minum obat secara teratur, serta komunikasi dalam bentuk menunjukkan penerimaan, mendengarkan dengan seksama, dan regulasi emosi saat berkomunikasi dengan ODS dapat memberikan penanganan yang tepat saat ODS mengalami gejala kekambuhan (relapse) sehingga dapat membantu proses perkembangan ODS.
\end{abstract}

Kata Kunci: komunikasi terapeutik, family caregiver, ODS, proses penyadaran, proses perkembangan

\section{PENDAHULUAN}

Skizofrenia merupakan penyakit mental yang disebabkan oleh ketidakseimbangan neurotransmitter dopamine pada otak. Skizofrenia merupakan salah satu penyakit gangguan mental berat yang cukup banyak ditemui di Indonesia. Persentase prevalensi skizofrenia di Indonesia mengalami peningkatan yang cukup signifikan dalam kurun waktu lima tahun. Hasil Riset Kesehatan Dasar (Riskesdas) pada tahun 2018 menunjukkan bahwa sebanyak $6,7 \%$ rumah tangga di Indonesia mempunyai anggota keluarga yang mengidap skizofrenia atau biasa disebut sebagai Orang Dengan Skizofrenia (ODS). Kecenderungan ini meningkat cukup signifikan jika dibandingkan dengan hasil Riskesdas pada tahun 2013 terkait persentase prevalensi skizofrenia yang hanya sebanyak 1,7\% (Riskesdas, 2013) ODS memiliki gejala halusinasi dan delusi sehingga mengakibatkan ODS cenderung mengalami kesulitan 
berkomunikasi dan menarik diri dari lingkungan sosial (Samsara, 2020). Keluarga memiliki peranan penting untuk berkomunikasi dan mengedukasi ODS terkait skizofrenia.

Skizofrenia sebetulnya sama dengan penyakit fisik lainnya yang perlu diobati agar penderitanya bisa sembuh dan tidak mengalami kekambuhan (relapse). Di Indonesia sendiri masih cukup banyak ODS yang belum memiliki kesadaran untuk rutin minum obat. Riskesdas (2018) mengungkapkan bahwa sebanyak 48,9\% ODS belum memiliki kesadaran untuk rutin minum obat secara teratur. Permatasari et al. (2011) mengungkapkan bahwa masih banyak keluarga dan family caregiver di Indonesia yang tidak memiliki edukasi yang memadai mengenai skizofrenia dan cara penanganannya. Hasil Riskesdas (2018) menunjukkan bahwa sebanyak $14 \%$ keluarga masih melakukan pemasungan kepada ODS. Lingkungan keluarga yang mendukung bisa memberikan dampak positif untuk proses penyadaran dan perkembangan ODS. Tola \& Immanuel (2015) mengungkapkan bahwa keluarga yang memberikan dukungan sosial kepada ODS bahkan bisa mempengaruhi kesadaran ODS untuk rutin minum obat secara teratur. Dukungan sosial dari keluarga juga bisa meningkatkan kualitas hidup ODS dan membentuk realisasi diri (Fiona, 2019).

Family caregiver merupakan anggota keluarga yang memiliki tanggung jawab untuk merawat anggota keluarga yang sakit secara sukarela (Caller et al., 2013). Seorang family caregiver harus memiliki edukasi yang memadai terkait penanganan ODS yang tepat. Gajali \& Badar (2016) menyebutkan bahwa family caregiver yang memiliki edukasi yang memadai bisa meningkatkan kemampuan psikomotor dalam merawat ODS. Pemahaman family caregiver terkait kondisi ODS akan memudahkan family caregiver berkomunikasi dengan ODS. Hal ini menjadi penting karena family caregiver memiliki peranan dalam berkomunikasi dan berinteraksi dengan ODS yang memiliki kecenderungan untuk menarik diri dari lingkungan sosial.
Komunitas Peduli Skizofrenia Indonesia (KPSI) merupakan sebuah komunitas yang bertujuan untuk memberikan edukasi mengenai skizofrenia. KPSI menampung ODS, caregiver dan juga masyarakat luas yang ingin mengedukasi dirinya terkait skizofrenia dan cara penanganannya. Komunitas ini didirikan oleh Bagus Utomo, salah satu family caregiver yang sudah merawat dan memberdayakan ODS selama kurang lebih 15 tahun. Bagus mendirikan KPSI dengan harapan bisa menjadi wadah bagi ODS maupun caregiver untuk saling bertukar informasi mengenai skizofrenia, berkeluh kesah, berbagi afirmasi positif, dan saling memberikan motivasi untuk tetap semangat (Ramadhana, 2018). Komunitas ini juga memiliki berbagai kegiatan untuk family caregiver seperti sesi webinar, terapi seni, dan kelompok swabantu untuk mengedukasi family caregiver mengenai skizofrenia dan memberikan penanganan yang tepat kepada ODS.

Komunikasi kesehatan merupakan salah satu jenis komunikasi yang bisa membantu proses pemulihan ODS dengan memberikan pesan edukasi yang bersifat persuasif. Pesan di dalam komunikasi kesehatan dapat mempengaruhi sikap, perilaku, dan pandangan resipien sehingga bisa meningkatkan kualitas kesehatan secara keseluruhan (Wilujeng \& Handaka, 2017). Komunikasi kesehatan memiliki beberapa bagian, salah satunya adalah komunikasi terapeutik. Komunikasi ini bertujuan untuk membantu proses terapi dan penyembuhan pasien. Lalongke \& Edison (2014) menyebutkan bahwa komunikasi terapeutik bertujuan untuk meringankan beban pikiran, mengurangi keraguan, dan memberikan saran untuk mengubah situasi menjadi lebih baik. Penggunaan komunikasi terapeutik juga bisa membuat ODS memiliki realisasi diri dan kesadaran, meringankan beban pikiran, hingga memperbaiki hubungan interpersonal ODS.

Berdasarkan penelitian terdahulu, terdapat hubungan positif antara penggunaan komunikasi terapeutik dalam perawatan ODS. Hasil penelitian Wahyuningsih et al. (2019) menggunakan metode studi kasus untuk 
mendalami metode dan strategi komunikasi terapeutik yang dilakukan oleh perawat. Terdapat beberapa metode yang bisa digunakan dalam komunikasi terapeutik untuk proses perawatan berkelanjutan Orang Dengan Gangguan Jiwa (ODGJ) pasca pasang. Metodemetode tersebut di antaranya dengan menggunakan telepsychiatry (konsultasi melalui video conference) hingga pelatihan mengasah keterampilan seperti kerajinan tangan. Aktivitas terapeutik yang dilakukan kepada ODGJ pasca pasung ini bisa mengasah keterampilan ODGJ. Selain itu, metode-metode ini juga bisa membuat ODGJ lebih terlatih untuk lebih mandiri dan siap untuk kembali ke masyarakat. Hasil penelitian ini juga menunjukkan bahwa komunikasi terapeutik merupakan elemen penting dalam proses penyembuhan pasien. Melalui komunikasi terapeutik, ODS juga lebih mudah untuk menjelaskan kondisi kesehatan yang dialaminya.

Penelitian ini membahas lebih dalam terkait pengalaman family caregiver dalam menggunakan komunikasi terapeutik. Keluarga memiliki peranan dalam berkomunikasi dan berinteraksi dengan ODS, terutama karena ODS memiliki kecenderungan untuk menarik diri dari lingkungan sosial. Lingkungan keluarga yang mendukung untuk mengedukasi, mendampingi, dan juga menerapkan komunikasi terapeutik dapat membantu proses pemulihan ODS. Penelitian ini berbeda dengan penelitian terdahulu yang kebanyakan membahas tentang penggunaan komunikasi terapeutik yang dilakukan oleh tenaga klinis seperti dokter, perawat, dan psikiatri dengan ODS. Penelitian ini memiliki kebaruan karena subjek penelitian merupakan family caregiver anggota KPSI dalam menggunakan komunikasi terapeutik dengan ODS. Penelitian ini menggunakan studi fenomenologi untuk mengkaji lebih dalam terkait pengalaman komunikasi terapeutik family caregiver anggota KPSI yang dikonstruksikan dalam proses penyadaran dan perkembangan ODS. Berdasarkan uraian signifikansi penelitian di atas, maka peneliti merumuskan pertanyaan penelitian yaitu:
Bagaimana pengalaman komunikasi terapeutik family caregiver anggota KPSI dalam proses penyadaran dan perkembangan ODS?

\section{METODOLOGI PENELITIAN}

Penelitian ini menggunakan pendekatan kualitatif. Pendekatan kualitatif berfokus pada proses penelitian secara alamiah, interpretasi, dan menekankan pada makna dari partisipan. Penelitian ini berusaha mencari makna dari sebuah fenomena berdasarkan pemahaman dan pengalaman partisipan yang merupakan family caregiver anggota KPSI yang didapat dari hasil wawancara mendalam. Pendekatan peneliti yang berfokus pada proses, pengalaman, dan interpretasi partisipan membuat peneliti memilih pendekatan kualitatif sebagai pendekatan yang paling sesuai untuk penelitian ini. Penelitian ini memiliki jenis field research, karena peneliti secara langsung berinteraksi dengan partisipan melalui wawancara mendalam yang dilakukan secara daring.

Penelitian ini berfokus kepada pengalaman komunikasi terapeutik berdasarkan interpretasi family caregiver anggota KPSI, sehingga peneliti memilih metode fenomenologi untuk penelitian ini. Alasan peneliti menggunakan metode fenomenologi adalah karena fokus penelitian ini merupakan pengalaman family caregiver ODS secara personal. Peneliti melihat bagaimana cara family caregiver ODS menilai pengalaman itu sendiri sesuai dengan realita yang dialami, terlepas dari fakta-fakta dan teori ilmu pengetahuan yang ada. Peneliti mengonstruksikan pengalaman komunikasi terapeutik family caregiver berdasarkan model interpretasi subyektif menurut Schutz dalam (Nindito, 2005). Peneliti mengategorisasi tindakan family caregiver dan hasil makna subyektif dari tindakan atau hasil tindakan yang dilakukan oleh family caregiver, sehingga menghasilkan konstruksi proses penyadaran dan perkembangan ODS. Peneliti mengategorisasi tindakan family caregiver dan hasil makna subyektif dari tindakan atau hasil tindakan yang dilakukan oleh family caregiver, sehingga menghasilkan konstruksi proses penyadaran dan perkembangan ODS. Metode 
fenomenologi yang digunakan memiliki sifat deskriptif, karena fenomenologi menggunakan data berupa cerita dan ungkapan dari partisipan. Peneliti menafsirkan dan menganalisis data sesuai dengan gambaran dan ungkapan apa adanya yang disampaikan oleh partisipan.

Tujuan dari penelitian ini adalah untuk mencari tahu mengenai pandangan partisipan terkait situasi yang sedang dialami. Peneliti menggunakan paradigma konstruktif agar dapat membuat partisipan lebih leluasa untuk mengutarakan pandangannya terkait suatu hal dan peneliti bisa mendapatkan jawaban dari perspektif yang lebih luas dan beragam. Alasan peneliti menggunakan paradigma ini adalah karena peneliti percaya bahwa ilmu bukan hanya berasal dari prosedur baku dan memiliki jawaban pasti.

Peneliti menggunakan teknik in-depth interview atau wawancara mendalam kepada family caregiver anggota KPSI dalam mengumpulkan data primer. Sebelum melakukan wawancara, peneliti mengajukan Ethical Approval Letter atau Surat Kajian Etik Penelitian dari Komite Etik Penelitian UPNVJ untuk memenuhi standar etis penelitian yang melibatkan family caregiver sebagai informan. Peneliti juga memberikan lembar penjelasan penelitian dan lembar informed concern yang berisikan persetujuan dari informan untuk menjadi partisipan dalam penelitian ini. Peneliti dan keenam informan juga membuat kesepakatan untuk melakukan wawancara secara daring karena situasi pandemi COVID19 yang sedang terjadi.

Wawancara daring dilakukan melalui pesan suara via WhatsApp voice call. Peneliti mengambil subjek penelitian family caregiver anggota KPSI yang berjumlah enam orang perempuan yang berusia 28-59 tahun. Tiga orang informan dalam penelitian ini sudah menjadi family caregiver ODS selama lebih dari sepuluh tahun, dan tiga orang lainnya sudah menjadi caregiver selama lebih dari satu tahun. Keenam informan memiliki hubungan keluarga inti dengan ODS, Informan A merupakan anak dari ODS, Informan B merupakan kakak dari ODS, Informan $\mathrm{C}$ merupakan adik dari ODS,
Informan D merupakan ibu dari ODS, Informan E merupakan anak dari ODS, dan Informan F merupakan ibu dari ODS.

Teknik analisis data yang digunakan untuk mengonstruksi pengalaman komunikasi terapeutik family caregiver anggota KPSI dalam proses penyadaran dan perkembangan ODS ini menggunakan metode analisis data fenomenologi menurut Giorgi dalam (Raco \& Tanod, 2012) Pertama-tama peneliti memahami bahwa setiap ucapan dan perkataan partisipan adalah data, dan peneliti juga harus menerima apa adanya semua yang diungkapkan oleh partisipan tanpa praduga dan prasangka. Selanjutnya, peneliti merekam hasil wawancara dan menulis kembali hasil wawancara dalam bentuk transkrip untuk memudahkan peneliti menganalisis data. Tahapan selanjutnya adalah menganalisis data dimulai dari familiarisasi atau membaca secara keseluruhan ungkapan yang disampaikan oleh partisipan dan mengelompokkan data tersebut berdasarkan konstruksi penelitian untuk mendapat gambaran umum dari informasi. Tahapan ini bertujuan untuk memahami bahasa partisipan dan mendapatkan gambaran pengalaman secara keseluruhan. Kedua, penentuan unit makna. Pada proses penentuan unit makna, peneliti membuat transformasi data mentah partisipan menjadi data yang memiliki arti pada topik penelitian, pada tahapan ini juga ungkapan harian partisipan diubah menjadi bahasa ilmiah. Ketiga, peneliti melihat dan membaca lagi seluruh unit makna dan dikonfrontir lagi dengan data asli partisipan untuk melihat keterkaitan dengan topik yang dibahas. Tahap terakhir yaitu membuat sintesa. Peneliti menyintesiskan dari semua unit makna yang kemudian ditransformasi dalam satu statement yang sesuai dengan pengalaman partisipan. Sintesa akan menghasilkan pengertian umum yang sesuai dengan konstruksi proses penyadaran dan perkembangan yang dibangun sesuai dengan fokus penelitian.

\section{HASIL DAN PEMBAHASAN}

Hasil penelitian ini digambarkan berdasarkan rumusan pertanyaan penelitian, 
fokus, dan tujuan penelitian yang akan menyajikan pengalaman komunikasi terapeutik family caregiver proses penyadaran dan perkembangan ODS. Peneliti melakukan wawancara secara mendalam kepada enam orang informan penelitian melalui voice call WhatsApp. Peneliti melakukan proses wawancara secara daring karena situasi pandemi yang tidak memungkinkan peneliti untuk bertemu langsung dengan informan. Keenam informan dalam penelitian ini memilih untuk melakukan wawancara melalui pesan suara (voice call) dibanding pesan video seperti Google Meet. keenam informan merupakan perempuan dengan usia yang bervariasi dari usia termuda 28 tahun sampai usia tertua 59 tahun. Karakteristik keenam informan dapat dilihat lengkap pada tabel 1 berikut:

Tabel 1. Karakteristik Informan

\begin{tabular}{|c|c|c|c|c|c|c|}
\hline Kategori & I.A & I.B & I.C & I.D & I.E & I.F \\
\hline $\begin{array}{l}\text { Inisial } \\
\text { Nama }\end{array}$ & V.S. & N.R. & N.R. & T.H. & $\mathrm{F}$ & $\mathrm{M}$ \\
\hline $\begin{array}{l}\text { Jenis } \\
\text { Kelamin }\end{array}$ & Perempuan & Perempuan & Perempuan & Perempuan & Perempuan & Perempuan \\
\hline Umur & 29 th & 38 th & 28 th & 59 th & 34 th & 54 th \\
\hline Pendidikan & $\mathrm{S} 1$ & SMA & S1 & SMA & $\mathrm{SD}$ & SMA \\
\hline Pekerjaan & Perawat & IRT & IRT & Akuntan & $\begin{array}{l}\text { Penjual } \\
\text { Online } \\
\text { Shop }\end{array}$ & $\begin{array}{l}\text { Guru Al- } \\
\text { Qur'an }\end{array}$ \\
\hline $\begin{array}{l}\text { Hubungan } \\
\text { dengan } \\
\text { ODS }\end{array}$ & $\begin{array}{l}\text { Anak dari } \\
\text { ODS }\end{array}$ & $\begin{array}{l}\text { Kakak dari } \\
\text { ODS }\end{array}$ & $\begin{array}{l}\text { Adik dari } \\
\text { ODS }\end{array}$ & $\begin{array}{ll}\text { Ibu } & \text { dari } \\
\text { ODS } & \end{array}$ & $\begin{array}{l}\text { Anak dari } \\
\text { ODS }\end{array}$ & $\begin{array}{l}\text { Ibu } \\
\text { ODS }\end{array}$ \\
\hline $\begin{array}{l}\text { Lama } \\
\text { merawat } \\
\text { ODS }\end{array}$ & 15 th. & 1 th. & 9 th. & 7 th. & 3 th. & 5 th. \\
\hline
\end{tabular}

Sumber: Penelitian, 2021

Keenam informan dalam penelitian ini memberikan gambaran bagaimana pengalaman informan dalam menggunakan komunikasi terapeutik dalam membantu proses penyadaran atau realisasi diri ODS. Proses penyadaran dalam komunikasi terapeutik meliputi pengirim pesan (inisiator), pesan yang bersifat terapeutik, penerima (komunikan), konteks, dan efek yang dihasilkan dari proses komunikasi. Pengirim pesan atau inisiator saat berkomunikasi sebagian besar dilakukan oleh family caregiver dengan ODS sebagai komunikan. Family caregiver mengungkapkan bahwa dalam berkomunikasi dengan ODS, mereka harus aktif untuk memberikan pertanyaan terkait kondisi yang dialami agar ODS dapat lebih terbuka untuk mengungkapkan perasaannya, sebab ODS memiliki kecenderungan untuk menarik diri dalam berinteraksi dengan lingkungan sekitar. Gading et al. (2018) yang mengungkapkan bahwa dengan menanyakan pertanyaan yang berkaitan, family caregiver bisa mendapatkan data yang diperlukan dalam memahami kondisi ODS untuk kemudian dikonsultasikan dengan psikiatri saat konsultasi. Hal ini juga sesuai dengan hasil penelitian Outram et al. (2015) yang mengungkapkan tentang pentingnya pengetahuan yang dimiliki oleh family caregiver terkait kondisi yang dialami oleh ODS. Hasil penelitian ini mengungkapkan bahwa family caregiver harus dilibatkan dalam diskusi dengan psikiatri untuk memudahkan psikiater dalam mengambil tindakan yang dapat membantu proses pemulihan ODS.

Pesan yang bersifat terapeutik digunakan oleh family caregiver saat berkomunikasi dengan ODS. Mendengarkan dengan seksama merupakan salah satu teknik komunikasi terapeutik yang digunakan. Saat berkomunikasi dengan ODS, family caregiver menggunakan teknik komunikasi mendengarkan dan menanggapi secara saksama 
cerita ODS. Mendengarkan dengan saksama merupakan bagian dari tahapan pra-interaksi dalam komunikasi terapeutik. Tahapan prainteraksi bertujuan untuk memahami secara menyeluruh mengenai kondisi yang dialami oleh ODS (Lalongke \& Edison, 2014). Proses mendengarkan dengan saksama dan memposisikan diri sebagai pendengar yang baik bisa membantu untuk memahami perasaan dan kondisi ODS. Family caregiver mengungkapkan bahwa dalam proses mendengarkan, family caregiver juga berperan aktif dalam memberikan penjelasan mengenai gejala halusinasi yang dialami. Hal ini dilakukan untuk menumbuhkan kesadaran ODS bahwa halusinasi yang dipahami bukan merupakan hal yang nyata. Teknik komunikasi yang dapat digunakan dalam menanggapi cerita ODS adalah dengan berbagi persepsi dan refleksi.

Family caregiver juga memberikan kesempatan kepada ODS untuk mengungkapkan persepsi yang dimiliki terkait gejala kekambuhan yang dialami, namun family caregiver juga tetap bertindak aktif dan kritis untuk menyampaikan persepsi dalam membangun kesadaran ODS mengenai gejala kekambuhan seperti halusinasi dan waham yang dialami. Family caregiver juga mengungkapkan bahwa dalam proses berbagi persepsi, terkadang ODS tidak mau menerima persepsi dan masukan dari family caregiver, maka untuk menanggapi hal tersebut family caregiver tidak akan memaksakan pemahaman yang dimiliki. Memberikan saran dan masukan kepada ODS juga merupakan pesan terapeutik yang digunakan dalam membangun kesadaran ODS. Family caregiver mengungkapkan bagaimana perubahan yang dialami ODS saat kondisinya sedang mengalami gejala kekambuhan dan bagaimana kemudian mereka mencoba untuk memahami dengan memberikan saran untuk membantu mengatasi permasalahan yang dialami ODS. Memberikan saran merupakan hal yang penting, karena di dalamnya terdapat edukasi ODS mengenai skizofrenia seperti pengertian mengenai halusinasi yang dialami oleh ODS, dan juga memberikan alternatif ide untuk pemecahan masalah yang dihadapi ODS.
Fadli \& Mitra (2013) mengungkapkan bahwa ekspresi emosi juga merupakan hal yang penting untuk diperhatikan dalam berkomunikasi dengan ODS. Ekspresi emosi yang negatif seperti menunjukkan permusuhan dan menggunakan nada tinggi dalam memberikan saran maupun kritik dapat membuat tingkat kekambuhan ODS semakin tinggi.

Penggunaan komunikasi non-verbal dan penyampaian pesan melalui tindakan secara implisit dapat membantu menumbuhkan kesadaran ODS mengenai skizofrenia. Family caregiver mengungkapkan bahwa dengan menunjukkan dari perilaku seperti rutin mengingatkan minum obat, menunjukkan penerimaan, dan memperhatikan komunikasi non-verbal seperti raut wajah dan intonasi sehingga bisa menunjukkan sikap "ngemong" dapat membuat ODS menjadi lebih nyaman dalam berinteraksi sehingga lebih mudah untuk menumbuhkan kesadaran diri. Hal ini sesuai dengan hasil penelitian Widiyanto \& Rizki (2016) terkait penggunaan komunikasi nonverbal sangat diperlukan saat berkomunikasi dengan ODS. Hasil penelitian ini menunjukkan bahwa penggunaan komunikasi non-verbal seperti memperhatikan intonasi, kontak mata, dan menjaga posisi tubuh dapat membuat ODS merasa lebih dihargai hingga dapat menciptakan hubungan yang saling percaya antara family caregiver dengan ODS.

Pesan edukasi diberikan melalui konteks interpersonal antara family caregiver dan ODS juga digunakan dalam membangun kesadaran dan mengedukasi ODS mengenai skizofrenia. Family caregiver memberikan pesan edukasi bahwa skizofrenia merupakan penyakit medis yang perlu diobati agar bisa pulih. Pesan edukasi ini kemudian juga dapat mempengaruhi penyadaran ODS terkait skizofrenia dan menumbuhkan kesadaran untuk berobat secara medis. Mengedukasi dan memberikan pesan informasi bertujuan untuk membantu proses berpikir ODS tentang skizofrenia. Riyantie (2020) mengungkapkan bahwa komunikasi dalam konteks interpersonal yang berlangsung antara dua orang dapat menghasilkan efek dan umpan balik secara langsung. Komunikasi 
secara interpersonal juga efektif dalam merubah perilaku seseorang, terutama jika inisiator dan komunikan memiliki kesamaan makna dalam memahami suatu pesan. Komunikasi interpersonal dapat berjalan efektif jika komunikator menggunakan pendekatan yang argumentative dengan berusaha untuk menghindari pendekatan yang bersifat agresif baik secara verbal maupun non-verbal kepada komunikan dan sebaliknya (Hamzah, 2018). Apriliani \& Widiani (2020) juga mengungkapkan bahwa melalui hubungan interpersonal yang erat antara inisiator dan pasien, maka inisiator dan pasien dapat mendapatkan pengalaman belajar bersama dalam memperbaiki kondisi psikologis dan kejiwaan pasien. Komunikasi terapeutik merupakan hubungan yang di dalamnya terdapat proses bertukar pikiran, perasaan, dan pengalaman dalam membangun hubungan saling percaya antara inisiator dan pasien.

Efek yang dihasilkan dari penggunaan komunikasi terapeutik membantu ODS untuk memiliki pengetahuan dan kesadaran mengenai skizofrenia yang dialaminya. Penyadaran ini ditunjukkan dari bagaimana ODS menunjukkan penerimaan terkait penyakit skizofrenia yang dimiliki, lebih terbuka, memiliki kepatuhan untuk rutin minum obat secara teratur, dan memiliki semangat untuk bisa pulih. Hal ini sesuai dengan hasil penelitian Diorarta \& Pasaribu (2018) yang juga menggunakan metode fenomenologi mengungkapkan bahwa keluarga yang memiliki edukasi yang memadai mengenai skizofrenia dapat menjalankan fungsi perawatan kepada ODS. Keluarga membutuhkan dukungan informasi yang dapat membantu menekan stresor dalam merawat ODS. Keluarga juga dapat mempertahankan suasana rumah yang menyenangkan untuk menjaga perkembangan ODS. ODS menganggap bahwa sikap mencintai dan mendukung dari keluarga menjadi motivasi mereka untuk bisa pulih. Hamdani et al. (2018) juga mengungkapkan bahwa keluarga yang memberikan dukungan dan bersikap terapeutik dapat membantu menjaga kestabilan kondisi
ODS dan menumbuhkan kesadaran ODS untuk patuh dalam minum obat.

Family caregiver mengungkapkan gambaran pengalamannya dalam menggunakan komunikasi terapeutik untuk proses perkembangan ODS yang meliputi monitoring dan observasi yang dilakukan oleh family caregiver, pendampingan family caregiver saat berkonsultasi dengan psikiater, dan proses perkembangan ODS terkait kestabilan kondisi dan kemampuan berkomunikasi. Keenam informan memberikan gambaran pengalaman saat melakukan observasi dan monitoring perkembangan ODS. Proses observasi yang dilakukan oleh family caregiver berawal dari mengamati dan memahami hal-hal yang menjadi pemicu dan gejala kekambuhan (relapse) yang dialami ODS. Observasi dan monitoring termasuk dalam proses tahapan prainteraksi dalam komunikasi terapeutik. Observasi dan monitoring yang dilakukan oleh family caregiver meliputi pemahaman mengenai gejala dan pemicu ODS. Tahapan ini penting dilakukan agar family caregiver dapat memahami dan mengerti kondisi ODS. Tahapan pra-interaksi bertujuan untuk lebih memahami perasaan, harapan, kecemasan, trauma dan juga ketakutan ODS. Hal ini diperlukan agar family caregiver bisa betul-betul memahami kondisi ODS sehingga dapat membina hubungan yang saling percaya dan terbuka dalam proses komunikasi terapeutik. Hasil penelitian Fadli \& Mitra (2013) mengungkapkan tentang bagaimana pengetahuan keluarga merupakan hal yang penting dalam menangani ODS. Keluarga yang memahami dan mengerti kondisi serta gejala yang dialami oleh ODS akan lebih bisa berperan aktif dalam membantu proses pemulihan ODS.

Edukasi yang dimiliki family caregiver dalam memahami skizofrenia dan memberikan penanganan kepada ODS merupakan hal penting yang dapat membantu proses perkembangan ODS. Salah seorang Family caregiver mendapatkan edukasi dalam menangani ODS dan memberikan pengobatan secara medis kepada ODS melalui pendidikan formal sebagai mahasiswa ilmu keperawatan. 
Family caregiver mengungkapkan bahwa dengan latar belakang pendidikan yang dimiliki dapat membantu family caregiver dalam mengidentifikasi dan memberikan penanganan yang tepat kepada ODS. Hasil penelitian Susyanti \& Hapsari (2015) menunjukkan bahwa latar belakang pendidikan di bidang kesehatan bisa mempengaruhi tingkat pengetahuan seseorang tentang gangguan jiwa. Zahara et al. (2015) mengungkapkan bahwa pendidikan kesehatan yang dimiliki oleh keluarga dapat meningkatkan pengetahuan mengenai kondisi ODS dan cara memberikan penanganan yang tepat sehingga bisa membantu mengurangi kekambuhan yang dialami oleh ODS.

Dalam memberikan penanganan secara terapeutik, family caregiver menggunakan teknik komunikasi terapeutik dengan menunjukkan penerimaan dan mendengarkan dengan seksama cerita ODS. Family caregiver mengungkapkan bahwa saat menanggapi ODS bercerita cara menanganinya adalah dengan tidak membantah dan mendengarkan secara seksama cerita yang disampaikan ODS. Teknik komunikasi yang meliputi aspek non-verbal juga dibutuhkan agar komunikasi bisa tetap berjalan dengan efektif dan menghindari terjadinya kesalahpahaman meskipun ODS memiliki distorsi kognitif Aini \& Budiyono (2015)

Melakukan pendampingan ke psikiater merupakan salah satu hal yang dapat membantu proses perkembangan ODS. Family caregiver mengungkapkan bahwa psikiater memiliki peran dalam mengedukasi dan memberikan informasi kepada family caregiver dalam menangani ODS. Sebagian family caregiver mengungkapkan bahwa ODS lebih memiliki keterbukaan dalam menceritakan kondisi dan gejala yang dialami saat berkonsultasi dengan psikiater. Hal ini kemudian dapat membantu family caregiver dalam memahami kondisi ODS secara menyeluruh dan memberikan penanganan yang tepat kepada ODS. Hal ini sesuai dengan hasil penelitian Kurniawan et al. (2015) yang mengungkapkan bahwa proses konsultasi dengan dokter dapat menambah pengetahuan keluarga tentang cara merawat
ODS. Sari \& Fina (2011) juga mengungkapkan bahwa terdapat hubungan bermakna antara informasi yang diperoleh keluarga dari konsultasi dengan tenaga medis dengan pencegahan kekambuhan ODS.

Pada saat proses pendampingan, psikiater memberikan saran untuk family caregiver dalam berkomunikasi dengan ODS. Beberapa saran tersebut antara lain: regulasi emosi saat menghadapi ODS yang sedang mengalami relapse, menghindari ekspresi dan intonasi yang menunjukkan kekesalan, mendengarkan cerita ODS, dan membuat suasana hati ODS nyaman dengan menghindari ucapan yang bisa membuat tersinggung atau menuntut ODS. Teknik tersebut diperlukan agar ODS tidak semakin merasa tertekan dan marah sehingga dapat menjaga kestabilan kondisinya. Hal ini sesuai dengan hasil penelitian Eni \& Herdiyanto (2018) terkait bagaimana dokter dan perawat memiliki peranan penting dalam meningkatkan wawasan keluarga dalam memberikan penanganan kepada ODS yang relapse. Psikiater dapat memberikan informasi pencegahan dan penanganan relapse yang berguna untuk mengedukasi keluarga dalam memberikan penanganan kepada ODS.

Proses perkembangan ODS terkait kestabilan kondisi ditunjukkan dari berkurangnya gejala kekambuhan seperti halusinasi dan waham yang dialami. Sebagian family caregiver bahkan mengungkapkan bahwa ODS sudah tidak pernah mengalami halusinasi. Hal ini kemudian juga dapat mendorong kemandirian, tanggung jawab, dan kontrol terhadap diri sendiri. Family caregiver juga mengungkapkan bahwa dengan menggunakan komunikasi terapeutik, ODS memiliki kesadaran saat mengalami gejala kekambuhan sehingga bisa lebih mengontrol halusinasi yang dialami. Hal ini sesuai dengan hasil penelitian Apriliani \& Widiani (2020). Hasil penelitiannya menunjukkan bahwa penggunaan komunikasi terapeutik dapat meningkatkan kedekatan dan hubungan sehingga dapat menimbulkan ikatan rasa percaya satu sama lain. Hal ini kemudian dapat membantu ODS untuk lebih bisa mengontrol 
gejala kekambuhan dan mengurangi munculnya halusinasi. Hal ini juga diperkuat oleh hasil penelitian Jatmika et al. (2020) terkait bagaimana penggunaan komunikasi terapeutik dapat berperan dalam proses perkembangan ODS dan mempengaruhi penurunan gejala perilaku kekerasan yang dimiliki oleh ODS. Hal ini juga diperkuat oleh hasil penelitian Sebayang (2020) yang membahas terkait hubungan dukungan sosial keluarga dengan frekuensi kekambuhan ODS paranoid. Hasil penelitian ini menunjukkan bahwa terdapat hubungan bermakna antara dukungan sosial keluarga dan frekuensi kekambuhan ODS.

Perkembangan kemampuan berkomunikasi ODS juga terlihat dari ODS yang sudah memiliki inisiatif untuk memulai pembicaraan, mengajukan pertanyaan yang berkaitan dengan hal-hal yang sifatnya umum, dan memiliki keterbukaan untuk berinteraksi dengan lingkungan sekitar. Wahyuningsih et al. (2019) mengungkapkan bahwa keluarga memiliki peranan penting dalam berkomunikasi dengan ODGJ. Keluarga dapat membantu ODS dalam memulai hubungan interpersonal dengan lingkungannya. Keluarga harus bisa melakukan komunikasi dengan empat elemen dasar yaitu saling menghormati, memberikan informasi, partisipasi, dan berkolaborasi. Hal lain yang juga penting untuk diperhatikan adalah dengan tidak membedakan perlakuan ODS dengan anggota keluarga lain agar ODS tidak merasa diasingkan.

\section{SIMPULAN}

Pengirim pesan (inisiator) dalam berkomunikasi sebagian besar dilakukan oleh family caregiver kepada ODS sebagai komunikan, meskipun ada sebagian ODS yang juga berperan sebagai inisiator sehingga terjadi hubungan yang transaksional. Family caregiver menggunakan pesan yang bersifat terapeutik seperti: Memberikan pertanyaan terbuka, memberikan kesempatan untuk memulai berbicara, mendengarkan dan menanggapi dengan saksama, berbagi persepsi, refleksi, memberikan saran dan informasi. Pesan kesehatan yang disampaikan oleh family caregiver kepada ODS adalah edukasi skizofrenia merupakan penyakit medis sehingga diperlukan untuk minum obat secara rutin agar bisa pulih. Family caregiver juga secara berkala mengingatkan ODS untuk rutin minum obat secara teratur. Proses penyampaian pesan ini sebagian besar dilakukan dalam konteks interpersonal secara tatap muka sehingga terjadi timbal balik secara langsung. Penggunaan komunikasi non-verbal seperti menjaga intonasi suara dan ekspresi wajah yang tepat juga digunakan oleh family caregiver untuk menjaga perasaan ODS agar tidak tersinggung saat berkomunikasi. Penggunaan berbagai teknik komunikasi terapeutik menghasilkan efek berupa penerimaan diri ODS mengenai penyakitnya dan kesadaran ODS bahwa dirinya memiliki penyakit skizofrenia yang sama dengan penyakit fisik lain yang membutuhkan obat untuk diminum secara teratur.

Family caregiver melakukan observasi dan monitoring untuk memahami secara menyeluruh mengenai pemicu dan gejala ODS. Dalam memberikan penanganan secara terapeutik, family caregiver menggunakan beberapa teknik komunikasi seperti menunjukkan penerimaan, mendengarkan dengan saksama, dan regulasi emosi. Family caregiver juga melakukan pendampingan ke psikiater sehingga bisa mendapatkan informasi dan edukasi terkait kondisi ODS dan cara memberikan penanganan yang tepat untuk mendukung proses perkembangan ODS. Psikiater memberikan edukasi kepada family caregiver untuk memperhatikan komunikasi non-verbal seperti menjaga emosi, ekspresi, dan intonasi sehingga dapat lebih tenang saat menghadapi ODS yang mengalami gejala kekambuhan (relapse). Proses perkembangan yang ditunjukkan oleh ODS ditunjukkan dari semakin berkurangnya frekuensi gejala kekambuhan. ODS juga menunjukkan perkembangan komunikasi yang ditunjukkan dari inisiatif untuk memulai pembicaraan, kemampuan untuk berinteraksi dengan lingkungan sekitar, dan memiliki kemandirian untuk menjalani aktivitas sehari-hari. 


\section{DAFTAR PUSTAKA}

Aini, S., \& Budiyono, A. D. (2015). Terapi Keluarga pada Skizofrenia (Fokus pada Model Psikoedukasi). Family Therapy In Schizophrenia, 11, 12-22.

Apriliani, Y., \& Widiani, E. (2020). Penerapan Komunikasi Terapeutik Pada Pasien Skizofrenia Dalam Mengontrol Halusinasi Di RS Jiwa Menur Surabaya. NERS: Jurnal Keperawatan, 16(2), 61-74.

Caller, R., Crawley, H., Dunne, J., Jordan, A., Landsberg, P., Mohun, D., Pearmain, H., Taylor, D., \& Fuchs, A. (2013). CAREGIVER'S HANDBOOK (R. Mishara (ed.)). DK Publishing.

Diorarta, R., \& Pasaribu, J. (2018). Pengalaman Keluarga Merawat Penderita Skizofrenia Dengan Masalah Utama Perilaku Kekerasan. Jurnal Keperawatan, 10(2), 106-113.

Eni, K. Y., \& Herdiyanto, Y. K. (2018). Dukungan Sosial Keluarga terhadap Pemulihan Orang dengan Skizofrenia (ODS) di Bali. Jurnal Psikologi Udayana, 5(2), 268.

Fadli, S. M., \& Mitra, M. (2013). Pengetahuan dan Ekspresi Emosi Keluarga serta Frekuensi Kekambuhan Penderita Skizofrenia. Kesmas: National Public Health Journal, 7(10), 466.

Fiona, K. (2019). Pengaruh dukungan sosial terhadap kualitas hidup penderita skizofrenia. Jurnal Psikologi Kepribadian dan Sosial, Vol.02(03), 106-113.

Gading, A., Saragih, R., \& Indiarna, V. (2018). Teknik Komunikasi Terapeutik Perawat dalam Proses Penyembuhan Pasie Skizofrenia di RSJKO Soeprapto, Bengkulu Nasional Komunikasi. 02, 657-.

Gajali, \& Badar. (2016). Pengaruh family psychoeducation therapy terhadap kemampuan keluarga merawat psien skizofrenia dengan halusinasi di kota Samarinda Kalimantan Timur. Jurnal Husada Mahakam, IV(3), 151-161.

Hamdani, R., Haryanto, T., \& Dewi, N. (2018). Hubungan Dukungan Keluarga Dengan
Tingkat Kepatuhan Minum Obat Pada Pasien Skizofrenia. Jurnal Riset Kesehatan Nasional, 1(1), 1.

Hamzah, R. E. (2018). Pengembangan Hubungan Komunikasi Antarpribadi Dikalangan Mahasiswa. Jurnal Pustaka Komunikasi, 1(1), 180-187.

Jatmika, D. G. P., Triana, K. Y., \& Purwaningsih, N. K. (2020). Hubungan Komunikasi Terapeutik dan Risiko Perilaku Kekerasan pada Pasien Skizofrenia di Rumah Sakit Jiwa

Provinsi Bali. Jurnal Keperawatan Raflesia, 2(1), 1-10.

Kurniawan, H., Mirza, \& Raihan. (2015). Hubungan Lamanya Perawatan Pasien Skizofrenia Dengan Stres Keluarga. Jurnal Kedokteran Syiah Kuala, 15(3), 179189.

Lalongke, M., \& Edison, T. (2014). Komunikasi Terapeutik Pendekatan Praktisi Kesehatan. Graha Ilmu.

Nindito, S. (2005). Fenomenologi Alfred Schutz: Studi tentang Konstruksi Makna dan Realitas dalam Ilmu Sosial. Jurnal Ilmu Komunikasi.

Outram, S., Harris, G., Kelly, B., Bylund, C. L., Cohen, M., Landa, Y., Levin, T., Sandhu, H., Vamos, M., \& Loughland, C. (2015). "We didn't have a clue": Family caregivers' experiences of the communication of a diagnosis of schizophrenia. International Journal of Social Psychiatry, 61(1), 10-16.

Permatasari, L., Sriati, A., \& Widiastuti, M. (2011). Gambaran dukungan sosial yang diberikan keluarga dalam perawatan penderita skizofrenia di instalasi rawat jalan rumah sakit jiwa provinsi jawa barat. 1-15.

Raco, J. R., \& Tanod, R. R. (2012). Metode Fenomenologi Aplikasi Pada Entrepreneurship. Penerbit PT Grasindo.

Ramadhana, Y. (2018). Keterlibatan komunitas dalam penguatan keluarga dan penderita skizofrenia (Studi kasus: Komunitas Peduli Skizofrenia Indonesia (KPSI)). Bachelor's thesis, Jakarta: Fakultas Ilmu Sosial dan Imu Politik UIN Syarif 
Hidayatullah.

Riskesdas 2013, T. (2013). Riset Kesehatan

Dasar 2013. Badan Penelitian dan Pengembangan Kesehatan.

Riskesdas 2018, T. (2018). Laporan Nasional Riskesdas 2018. Badan Penelitian dan Pengembangan Kesehatan.

Riyantie, M. (2020). Manajemen Komunikasi Teraupetik Pada Penyembuhan. 19(2), 285-295.

Samsara, A. (2020). Mengenal Skizofrenia. National Institute of Mental Health, 0-31.

Sari, H., \& Fina, F. (2011). Dukungan Keluarga Dalam Mencegah Kekambuhan Pasien Skizofrenia Di Poliklinik Rawat Jalan Rsj Aceh. Idea Nursing Journal, 2(3).

Sebayang, S. (2020). Hubungan Dukungan Sosial Keluarga Dengan Frekuensi Kekambuhan Pasien Skizofrenia Paranoid Di Poliklinik Rs Jiwa Daerah Propsu Medan. Jurnal Ners Indonesia, Volume 6, Nomor 2, April 2020 14, 6(2), 14-20.

Susyanti, S., \& Hapsari, V. (2015). Hubungan Pengetahuan dan Sikap Tentang Penyakit Skizofrenia terhadap Stigma Masyarakat pada Penderita Skizofrenia di Desa Kersamanah Kecamatan Kersamanah Kabupaten Garut. Revista CENIC. Ciencias Biológicas, 152(3), 28.

Tola, B., \& Immanuel, N. L. (2015). Dukungan Sosial Dan Kepatuhan Minum Obat Pada
Pasien Skizofrenia Rawat Jalan. JPPP - $q$, 4(1), 7-11.

Wahyuningsih, S., Dida, S., Suminar, J. R., \& Setianti, Y. (2019). Aktivitas Komunikasi Keluarga Pasien, Kader Jiwa, Perawat Di Lingkungan Rumah Orang Dengan Gangguan Jiwa Pasca Pasung. Jurnal Ilmiah Permas: Jurnal Ilmiah STIKES Kendal, 9(3), 267-286.

Wahyuningsih, S., Dida, S., Suminar Ratna, J., \& Setianti, Y. (2019). Communication Activities of Family Patients, Soul Kader, Nursing in People, S House Environment With Post-Single Life Disorders. Jurnal Ilmiah STIKES Kendal, 9(3), 267-286.

Widiyanto, J., \& Rizki, Z. (2016). Penerapan Komunikasi Terapeutik Pada Pasien Halusinasi Di Rumah Sakit Jiwa Tampan Propinsi Riau. Photon: Jurnal Sain dan Kesehatan, 6(02), 101-107.

Wilujeng, C. S., \& Handaka, T. (2017). Komunikasi Kesehatan: Sebuah Pengantar. Universitas Brawijaya Press.

Zahara, R., Hizir, \& Hermansyah. (2015). Pendidikan Kesehatan Terhadap Peningkatan Pengetahuan Keluarga Penderita Skizofrenia dengan Perilaku Kekerasan Jurnal Ilmu

Keperawatan ISSN: 2338 - 6371, 134-146. 